
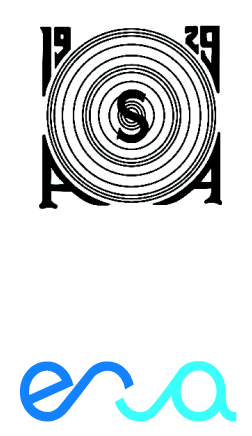

\title{
Assessment of military shooting noise
}

\author{
H. Boeglia , J.M. Wunderli ${ }^{\mathrm{b}}$ and M. Brink ${ }^{\mathrm{c}}$
}

${ }^{\text {a}}$ Federal Office for the Environment, BAFU, 3003 Bern, Switzerland

${ }^{b}$ EMPA - Materials Science and Technology, Ueberlandstr. 129, CH-8600 Duebendorf, Switzerland

${ }^{c}$ ETH Zürich, Center for Organizational and Occupational Sciences, LEO B 9.1, 8092 Zürich,

Switzerland

hans.boegli@bafu.admin.ch 
The assessment of the impact of noise exposure on the population is a fundamental step in noise abatement. It includes the establishment of exposure-response relationships and the setting of impact thresholds that specify the protection level for the population and eventually trigger mitigating measures to reduce noise exposure. In Switzerland, the impact thresholds should be set so that, in the light of the current scientific knowledge and experience, noise exposure below these thresholds do not seriously disturb the well-being of the population. For most current noise sources such as roads, railways and airports impact thresholds are already defined as part of the noise abatement legislation. Yet, no impact thresholds for military shooting grounds have been specified so far. Therefore a study was carried out in order to assess the impact of military noise exposure. The research included the calculation of noise exposure of eight military shooting grounds ranging from small infantry shooting ranges to expanded artillery and tank training facilities as well as a survey with over 1000 residents in the neighbourhood of these sites. Preliminary results suggest that although the responses of the population to military noise are rather dispersed, data should be sufficiently consistent to establish an exposure-response relationship.

\section{Introduction}

Noise abatement in Switzerland fully started in the early sixties with a parliamentary proposal to deal with the increasing noise exposure of the population and its negative effects on public health. The following years were marked by establishing an Environmental Protection Law (EPL) [1] in 1983 and elaborating a noise abatement policy. The latter was laid down in the Noise Abatement Ordinance [2] in 1987. In the following years this policy was supplemented with exposure limits for roads, railways, civil shooting ranges, industry and trade installations, civil and military airports as well as legal regulations for the Swiss railway noise remediation project [3], [4].

The policy [5] consists of six principles: The assessment principle defines and quantifies exposure-response relationships as well as critical levels or exposure limits for the most frequent types of noise for day and night. The source principle requires that noise abatement measures should be taken primarily at the noise source. If not practicable or too expensive, substitution measures in terms of noise protection of the buildings should be applied. Future noise problems (starting from 1985 when the EPL entered into force) should be avoided with the prevention principle which defines regulations at an early stage for both, noise emitters (emission and exposure limits) as well as noise receivers (restrictions and insulation regulations for constructing in noisy areas). The remediation principle compels old installations (those existing before 1985) to apply measures in order to respect the impact thresholds. While most of the action plans for installations such as industry and trade as well as shooting ranges have been completed, much remains to be done in the field of noise from streets and roads as well as railways and airports.

Costs are handled according to the polluter pays principle, however, there still remain external noise costs of at least 700 '000 Euros every year. The cooperation principle brings together players from various specialist areas in order to account for the highly interdisciplinary field of noise abatement. This approach is reflected by the close collaboration between the Confederation, the 26 cantons and the over 2700 local authorities that share the task of noise abatement.

While all the effort in noise abatement has remarkably reduced noise exposure from the most dominant sources, there are still missing exposure limits as well as actions plans for military shooting grounds. The present project is bound to tackle this problem.

\section{Method}

The method to establish noise exposure limits can be broken up into four steps: hazard identification, exposure assessment, establishing exposure-response relationships and setting exposure limits according to predefined health protection criteria. The following gives a short overview of the work that has been carried out in the project.

\subsection{Hazard identification}

The aim of the first step is to identify the relevant health effects of noise exposure. WHO lists several possible health effects (Table 1).

\begin{tabular}{|l|l|}
\hline pain and hearing fatigue & annoyance \\
\hline $\begin{array}{l}\text { hearing impairment } \\
\text { including tinnitus }\end{array}$ & $\begin{array}{l}\text { interference with speech } \\
\text { communication }\end{array}$ \\
\hline $\begin{array}{l}\text { sleep disturbance and all } \\
\text { its consequences on a long } \\
\text { and short term basis }\end{array}$ & $\begin{array}{l}\text { performance decrements at } \\
\text { work and/or school }\end{array}$ \\
\hline $\begin{array}{l}\text { interferences with social } \\
\text { behaviour (aggressiveness, } \\
\text { protest, helplessness) }\end{array}$ & $\begin{array}{l}\text { hormonal responses (stress } \\
\text { hormones) and their possible } \\
\text { consequences on human } \\
\text { metabolism (nutrition) and } \\
\text { immune system }\end{array}$ \\
\hline cardiovascular effects & \\
\hline
\end{tabular}

Table 1 Health effects from noise exposure [6].

In case of military shooting noise there is the danger of hearing impairment from loud blasts of light and heavy gun fire and explosions. However, the military personnel is supposed to be sufficiently protected by means of hearing protection devices and the nearest settlements are always too far away to reach sound pressure levels that can cause immediate damage to the ear. Moreover, in Switzerland, most training takes place during day-time or to a very limited extent also in the early evening hours, so that occurrences of relevant sleep disturbance can virtually be excluded. It was therefore assumed that the relevant health effect of military shooting noise is annoyance and that 
further health end points such as cardiovascular effects or hormonal responses can be avoided or minimized if annoyance does not occur.

The assessment of the degree of annoyance is generally carried out by surveys among the noise exposed population, using an annoyance scale from 0 to 10 . Bearing in mind that directly asking people about their perception of military noise exposure and annoyance could bias the responses, we developed a questionnaire that evaluated various criteria which contribute to living quality of the population. The survey included about 1000 persons in different communities who live in the neighbourhood of the eight biggest military shooting grounds. Each interview took about 15 minutes and was carried out by means of a computer aided telephone interview system at a market research bureau. All interviews were carried out between September and November 2007.

\subsection{Acoustical exposure}

Annoyance from noise of military shooting grounds is not among the most widespread in Switzerland, even though gun shots from light and heavy weapons can be frequently heard in the mountain valleys. With a population of 7.5 million inhabitants Switzerland has an army of approximately 200'000 soldiers. They serve on a regular basis on over 350 army installations and shooting grounds distributed all over the country (Fig. 1).

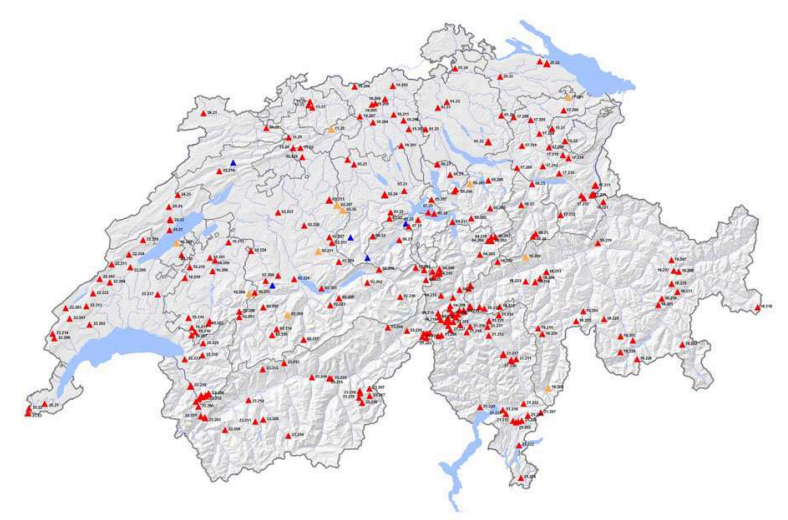

Fig.1 Military shooting grounds in Switzerland

Most of these grounds, however, are very small and their yearly activities are limited to only a few days. The biggest part of the shooting takes place on a dozen shooting grounds that contain small infantry shooting ranges as well as expanded artillery and tank training facilities. Noise exposure was calculated for the neighbouring population in order to carry out the survey. Every year, the shooting training of the army consists of something like 120'000 large calibre shots $(>50 \mathrm{~mm})$ and over 25 million small calibre shots. It must also be mentioned that apart from the military training there is a considerable civil shooting activity on over 2000 shooting ranges with over 75 million shots per year.

After the selection of eight of the most important shooting grounds, the input data for the calculation of the noise exposure was collected. It basically contained the identification of the weapons and ammunitions, the corresponding number of shots and shooting days, as well as the time distribution of the activity between day and evening. Based on this data a rough exposure map around the eight grounds was calculated. These noise maps together with demographic data from the last census were the basis to select the possible subjects who should take part in the survey.

Based on this survey, the addresses of those subjects who responded to the questionnaire could be extracted. Their noise exposure was exactly calculated, taking into account meteorological conditions and topological ground damping effects.

Military shooting noise can be assessed by several indicators. The most popular is the Leq that averages the sound level energy over a certain period of time. This indicator is sometimes complemented with correction factors, yielding a rating sound level $\mathrm{Lr}(=\mathrm{Leq}+\mathrm{k})$ that should correlate better with the noise effect in question. In Switzerland the $\mathrm{Lr}$ is used for noise sources such as traffic and industry infrastructures. However, the basis for the indicator for civil shooting ranges of light guns is not the Leq, but a compound measure. It includes the single event sound level (measured with fast setting), the number of shoots fired and the number of days when shooting takes place. For military shooting grounds, where heavy guns from Leopard II tanks, M109 howitzer and Haglund CV90 armoured personnel carriers as well as light guns like the Swiss assault rifle 90 are applied, the question therefore remained open. Preliminary results suggest that an energy equivalent unit such as Leq or LAE might be the most reliable basis for the exposure-response relationship.

\subsection{Exposure-Response Relationship}

The exposure-response relationship is established by correlating the "highly annoyed" data from the survey with the exposure data of the noise maps. In accordance with the international standards [7], the response was considered as "highly annoyed" if it is in the range of 8,9 or 10 on the scale between 0 and 10 . This is a rather conservative approach as the cut-off value for highly annoyed on a scale between 0 and 100 is usually considered to be 72 [8]. As mentioned above, several exposure indicators are evaluated in order to find the best predictor for high annoyance and the best might be the energy indicator LAE integrated over one year. From this, other indicators like Leq12h could be easily calculated. Although the annoyance-responses are rather widely distributed, the resulting curve (Fig.2) shows a typical increase in annoyance with increasing noise exposure and the confidence interval is in the range of $+/$ $5 \%$.

The questionnaire contained 30 questions in total and only one of them was asking for the degree of annoyance. Other questions covered additional aspects of noise exposure, such as time and duration of occurrence, character of noise, other noise sources, actions (complaints, etc.), noise sensitivity and attitude towards the army. The rest of the questions were used for control variables (age, sex, living conditions, profession, etc.). A more detailed description of the survey study and its evaluation can be found in the paper of Brink et al.[9]. 


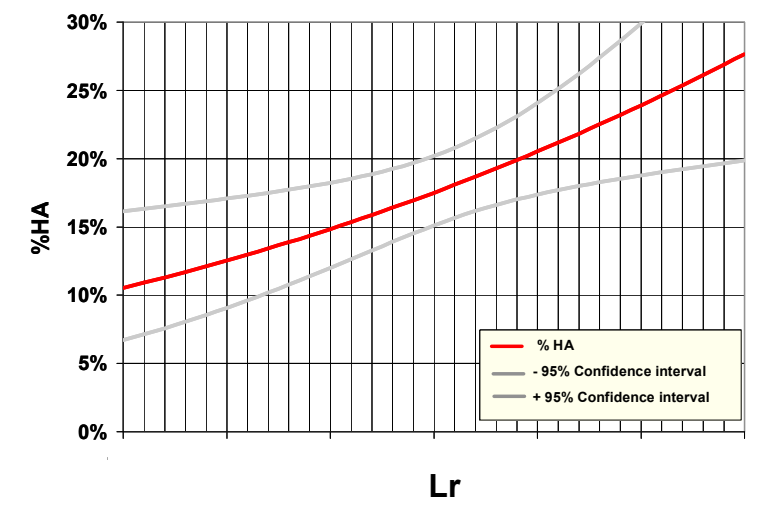

Fig.2 Exposure-response relationship for highly annoyance from noise of military shooting grounds (preliminary results)

\subsection{Setting of Exposure Limits}

In Switzerland three different types of exposure limits are defined:

- Impact threshold to ensure that noise below this level does not seriously disturb the well-being of the population.

- Planning values which are about $5 \mathrm{~dB}$ lower than impact thresholds and should concretize the prevention principle.

- Alarm values which are about $10 \mathrm{~dB}$ higher than the impact thresholds and indicate the urgency for remediation.

These values are defined for four sensitivity categories to account for their different sensitivity to noise disturbance (Fig. 3).

\begin{tabular}{l|c|c|c|c|c|}
\hline \multicolumn{5}{c}{} & \multicolumn{3}{c}{ Well-being of population not seriously disturbed } \\
\hline
\end{tabular}

Fig.3 The setting of exposure limits.

The relevant criterion for setting the impact thresholds is laid down in the EPL. It should be set so that, in the light of scientific knowledge and experience, noise exposure below these thresholds will not seriously disturb the well-being of the population. It is generally acknowledged that this limit is where a percentage of about 15 to $25 \%$ high annoyance can be expected. This final step has not been carried out yet, but will be based on the data obtained so far in the study. Once set the impact threshold for residential areas, the other values are set by reducing or increasing the levels by 5 or $10 \mathrm{~dB}$ according to the sensitivity categories and the type of the exposure limit (Fig 3).

\section{$3 \quad$ Further Steps}

The next step will be to discuss the present study with further experts in order to establish the results. The assessment method for military shooting grounds should also be adapted to the method for civil shooting ranges. The results will then be finalized into a proposal to the government to complement the noise abatement ordinance with the assessment method and exposure limits for military shooting grounds.

Although some mitigation measures for new or modified military installation have already been carried out over the last decades on the basis of a special arrangement with the army, an action plan is needed to improve all existing shooting grounds over a period of about 10 to 15 years in order to protect the population from noise of these installations.

\section{Conclusions}

The assessment of noise exposure by means of exposure limits is a fundamental and important step in noise abatement. The present study assesses military shooting noise on eight different grounds based on a phone survey to 1000 people. Results showed rather dispersed responses to noise. Nevertheless it is possible to establish an exposureresponse relationship and to set an impact threshold. Abatement measures for all military shooting grounds will be enforced as soon as the exposure limits are legally fixed in the noise abatement ordinance.

\section{Acknowledgments}

The support of the Federal Department of Defence, Civil Protection and Sports is gratefully acknowledged.

\section{References}

[1] Federal Law relating to the Protection of the Environment, Switzerland (1983), http://www.umweltschweiz.ch/imperia/md/content/recht/umweltrecht/usv bg-en.pdf.

[2] Noise Abatement Ordinance, Switzerland (1986), http://www.umweltschweiz.ch/imperia/md/content/recht/umweltrecht/lsv vo-en.pdf.

[3] Federal Act on Railways Noise Abatement, Switzerland (2000), http://www.umweltschweiz.ch/imperia/md/content/laerm/rechtstexte/1.pdf.

[4] Ordinance on Railways Noise Abatement, Switzerland (2001), http://www.umweltschweiz.ch/imperia/md/content/laerm/rechtstexte/3.pdf. 
[5] Noise abatement in Switzerland, status and perspectives, Environmental Series No. 329, FOE (2002), http://www.umwelt-

schweiz.ch/buwal/shop/files/pdf/phptBogWi.pdf.

[6] Main health effects of noise, WHO, http://www.euro.who.int/noise.

[7] ISO (International Organization for Standardization) 2003 ISO/TS 15666: Acoustics - Assessment of noise annoyance by means of social and socio-acoustic surveys.

[8] Synthesis of social surveys on noise annoyance, Schultz, T. J, Journal of the Acoustical Society of America, 64: 377-405 (1978).

[9] Community response to military shooting noise immissions, Mark Brink et al, Acoustics 08, June 29 July 4, 2008, Paris, France. 